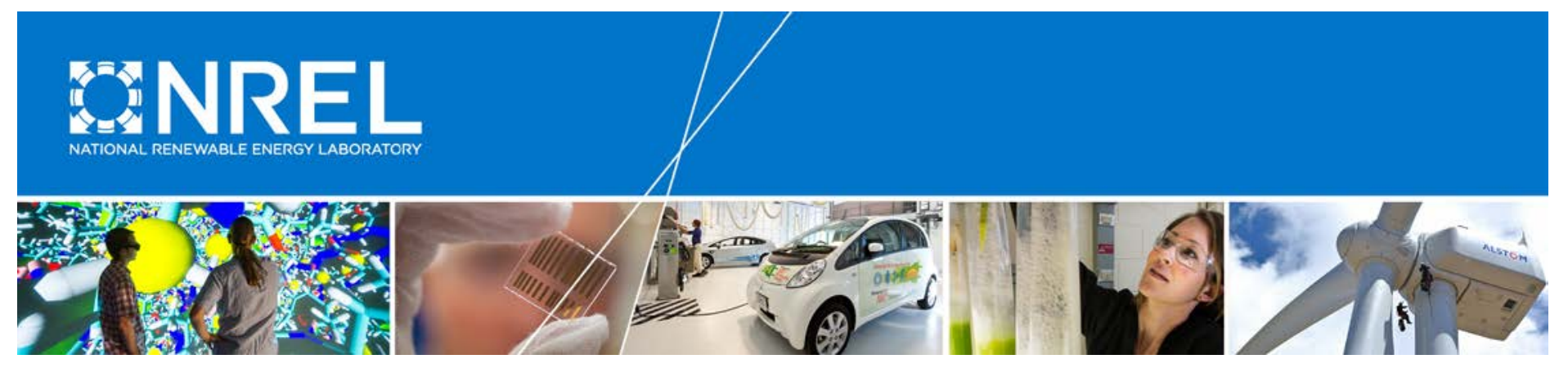

\title{
Empirical Investigations of the Opportunity Limits of Automatic Residential Electric Load Shaping
}

\section{Preprint}

Robert F. Cruickshank, Gregor P. Henze, and Rajagopalan Balaji University of Colorado

Bri-Mathias S. Hodge and Anthony R. Florita National Renewable Energy Laboratory

Presented at the IEEE Green Technologies Conference Denver, Colorado

March 29-31, 2017

(C) 2017 IEEE. Personal use of this material is permitted. Permission from IEEE must be obtained for all other uses, in any current or future media, including reprinting/republishing this material for advertising or promotional purposes, creating new collective works, for resale or redistribution to servers or lists, or reuse of any copyrighted component of this work in other works.

NREL is a national laboratory of the U.S. Department of Energy Office of Energy Efficiency \& Renewable Energy Operated by the Alliance for Sustainable Energy, LLC

This report is available at no cost from the National Renewable Energy Laboratory (NREL) at www.nrel.gov/publications.

Conference Paper

NREL/CP-5D00-67800

April 2017

Contract No. DE-AC36-08GO28308 


\section{NOTICE}

The submitted manuscript has been offered by an employee of the Alliance for Sustainable Energy, LLC (Alliance), a contractor of the US Government under Contract No. DE-AC36-08GO28308. Accordingly, the US Government and Alliance retain a nonexclusive royalty-free license to publish or reproduce the published form of this contribution, or allow others to do so, for US Government purposes.

This report was prepared as an account of work sponsored by an agency of the United States government. Neither the United States government nor any agency thereof, nor any of their employees, makes any warranty, express or implied, or assumes any legal liability or responsibility for the accuracy, completeness, or usefulness of any information, apparatus, product, or process disclosed, or represents that its use would not infringe privately owned rights. Reference herein to any specific commercial product, process, or service by trade name, trademark, manufacturer, or otherwise does not necessarily constitute or imply its endorsement, recommendation, or favoring by the United States government or any agency thereof. The views and opinions of authors expressed herein do not necessarily state or reflect those of the United States government or any agency thereof.

This report is available at no cost from the National Renewable Energy Laboratory (NREL) at www.nrel.gov/publications.

Available electronically at SciTech Connect http:/www.osti.gov/scitech

Available for a processing fee to U.S. Department of Energy and its contractors, in paper, from:

U.S. Department of Energy

Office of Scientific and Technical Information

P.O. Box 62

Oak Ridge, TN 37831-0062

OSTI http://www.osti.gov

Phone: 865.576.8401

Fax: 865.576.5728

Email: reports@osti.gov

Available for sale to the public, in paper, from:

U.S. Department of Commerce

National Technical Information Service

5301 Shawnee Road

Alexandria, VA 22312

NTIS http://www.ntis.gov

Phone: 800.553 .6847 or 703.605 .6000

Fax: 703.605.6900

Email: orders@ntis.gov 


\section{Empirical Investigations of the Opportunity Limits of Automatic Residential Electric Load Shaping}

\author{
Robert F. Cruickshank III, Gregor P. Henze and \\ Rajagopalan Balaji \\ Civil, Environmental and Architectural Engineering \\ University of Colorado \\ Boulder, Colorado, USA \\ Robert.CruickshankIII@colorado.edu \\ Gregor.Henze@colorado.edu \\ balajir@colorado.edu
}

\author{
Bri-Mathias S. Hodge and Anthony R. Florita \\ Power Systems Engineering Center \\ National Renewable Energy Laboratory \\ Golden, Colorado, USA \\ Bri.Mathias.Hodge@nrel.gov \\ Anthony.Florita@nrel.gov
}

\begin{abstract}
Residential electric load shaping is often implemented as infrequent, utility-initiated, short-duration deferral of peak demand through direct load control. In contrast, investigated herein is the potential for frequent, transactive, intraday, consumer-configurable load shaping for storage-capable thermostatically controlled electric loads (TCLs) including refrigerators, freezers, and hot water heaters. Unique to this study are 28 months of 15-minute-interval observations of usage in 101 homes in the Pacific Northwest United States that specify start, duration, and usage patterns of approximately 25 submetered loads per home. The magnitudes of the load shift from voluntarily-participating TCL appliances are aggregated to form hourly upper and lower load-shaping limits for the coordination of electrical generation, transmission, distribution, storage, and demand. Empirical data are statistically analyzed to define metrics that help quantify load-shaping opportunities.
\end{abstract}

Index Terms-demand response, load management, load modeling, price response, transactive energy.

\section{INTRODUCTION}

To minimize the cost of generation, transmission, and distribution, increasing numbers of smart home Internet of things can transition from autonomous operation to orchestrated operation. Instead of local start and stop control, thermostatically controlled electric loads (TCLs) such as refrigerators, freezers, and hot water heaters can be networked to efficiently harmonize with fixed and mobile (vehicle) batteries and solar photovoltaic panels to save consumers money by continuously updating and implementing least-cost operating strategies. In this fashion, instead of electrical supply meeting demand, incentive signals become increasingly important in encouraging demand to help meet supply, thereby reducing greenhouse gas emissions and the curtailment of clean energy.

Despite ever-increasing complexity, the evolving electric

This work is supported in part by the U.S Department of Energy (DOE) under Contract No. DE-AC36-08GO28308 with the National Renewable Energy Laboratory. Funding provided by the DOE Office of Energy Efficiency and Renewable Energy Building Energy Technologies Program. grid is highly reliable and capable [1]. To accommodate vast spatiotemporal changes in net load, expensive marginal generation and reserve capacity are dispatched as needed. Due to declining costs, variable and uncertain renewable energy sources (RES) are becoming more prevalent and will likely dominate worldwide electricity supply [2]. Several states and nations aspire to high penetrations of RES - e.g., as high as $100 \%$ by 2050 [3]. Because RES are often much less dispatchable, a significant challenge in maximizing the use of clean energy is the continuous shaping of electrical load among all users via demand response strategies, including real-time pricing. This load shaping supports efficient grid operation and can be unnoticeable to consumers while providing cost savings to all supply and end-use stakeholders.

A recent review of this research area [4] suggests the following goals: (1) identify state-of-the-art, system-level price response models involving time-elastic end uses in residential buildings, (2) identify price-response-modeling gaps, (3) identify price-response human behavioral issues, and (4) provide recommendations for future price-response research. The review primarily reveals an overall scarcity of system-level models and a plethora of subsystem models with limited or unspecified spatiotemporal resolutions. Although models of the impact of demand response on end-to-end system performance have been developed, the extent to which existing models provide comprehensive answers in a rapidly evolving grid is debatable. The review suggests that further empirical, bottom-up, end-to-end system models are needed to simulate and optimize the impact of demand response on maximizing the efficient use of RES. Reference [5] suggested that demand response measures will no longer need to simply decrease the electric load during easily predictable, high-price, load-peak periods and/or increase it during low-price, loadvalley periods. In the future, significantly less predictable and more volatile net load after renewable generation (i.e., the consumed load less the generation from RES [6], [7]) will need to be smoothed by demand response. As such, the novelty of this work is the preliminary evaluation of empirical (in-home metering) measurements as potential seeds for the 
future creation and scaling of realistic residential demand profiles to help quantify the demand response impact of automatic residential load shaping (ARLS) on the grid.

The following sections describe continuous intra-hour ARLS, wherein each individual appliance may autonomously execute different on and off set points based on a two-state price of electricity. When the price of electricity is high, for example, ARLS models the temperature of a domestic hot water (DHW) heater as further decaying before starting electric resistance heating. Correspondingly, when the price of electricity is low, ARLS models heat the water to a higher temperature. Unlike direct load control, in ARLS it is imagined that a consumer can login to their appliance(s) to increase or decrease the impact of pricing.

\section{RESIDENTIAL BUILDING STOCK ANALYSIS}

All data in this study come from the Northwest Energy Efficiency Alliance, Residential Building Stock Analysis (NEEA RBSA), based on field data from a representative random sample of existing homes [8], [9]. The NEEA RBSA encompasses 28 months of 15-minute observations in singlefamily homes in the Pacific Northwest of the United States. In addition to whole-building electricity use, there are typically 25 submetered loads per home, including various types of heating, ventilating, and air-conditioning (HVAC) systems; appliances; lighting; entertainment; home office; and plug loads. The Pacific Northwest had little precedent for a residential field study of this size and nature; thus, it was a new standard for residential characterization studies in the region. The 2009 International Energy Conservation Code (IECC) classifies NEEA RBSA metered homes in IECC climate zones 4, 5, and 6 [10].

\section{A. NEEA RBSA Reports}

The first NEEA RBSA report [8] contains attributes of 1,400 single-family homes, as shown in Fig. 1. In addition to quantitative building age and envelope measurements, a cross section of age and type of appliances is included.

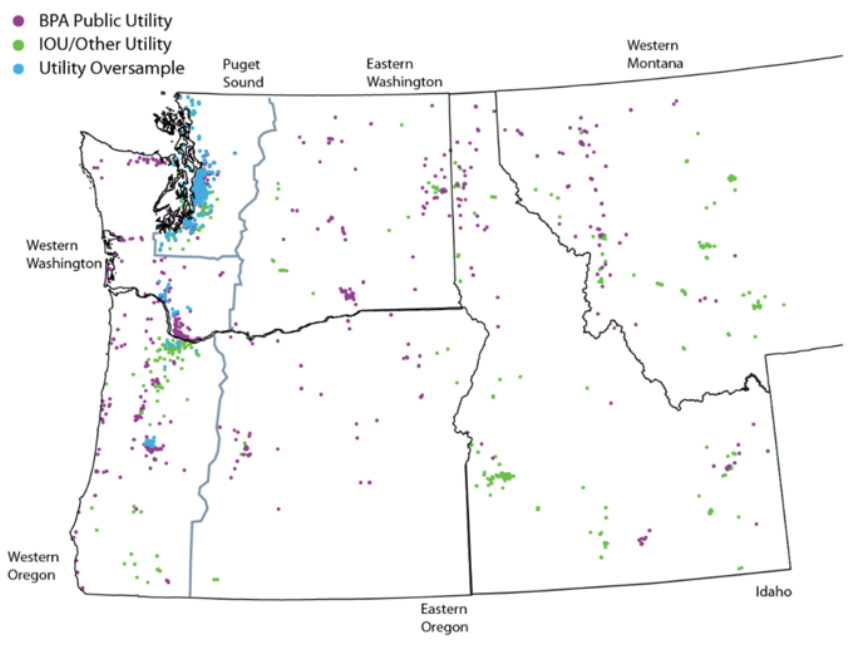

Figure 1. Homes in 2011 NEEA RBSA Attribute report include all public and investor-owned utilities in WA, OR, ID and Western MT.

The second NEEA RBSA report [9] covers a subset of 101 homes and submetered loads therein, which are the data used in this study. The TCL appliance data reveal how each device could act in a demand response capability, and the 15-minute sampling interval allows for the creation of detailed load shapes.

\section{B. Overview of NEEA RBSA Submetered Data}

The NEEA RBSA submetered data reflect diversity among homes, appliances, occupancy patterns, hour of day, day of week, seasons, holidays, shopping cycles, home chore cycles, vacations, etc. Vigilance around data hygiene is critical during extraction, transformation, and loading of data. Some data are out of range (positive and negative), and others are missing; data issues bring into question completeness of acquisition, accuracy of processing, and the possibility that an appliance was set back or turned off for hours, days, weeks, or months. Appendix A contains sample data records from one home.

The bar charts in Fig. 2 show when the appliance is turned on in black and off in white. Individual bar width is 15 minutes, and the height of each bar is the kilowatt-hours of energy used in that 15 minutes. A large black region indicates a long run time-for example, a refrigerator cooling down after a grocery refill. (a) Refrigerator 24684

0.1 (b) Freezer 24203

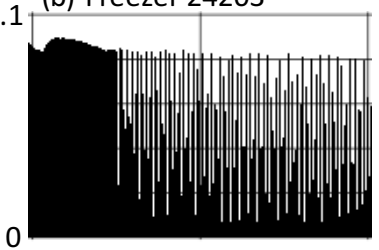

(c) DHW 24684

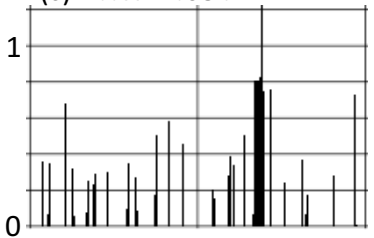

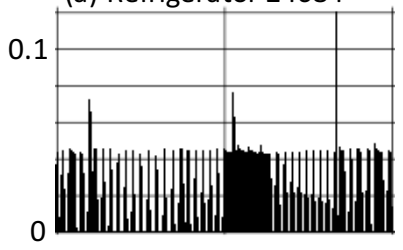
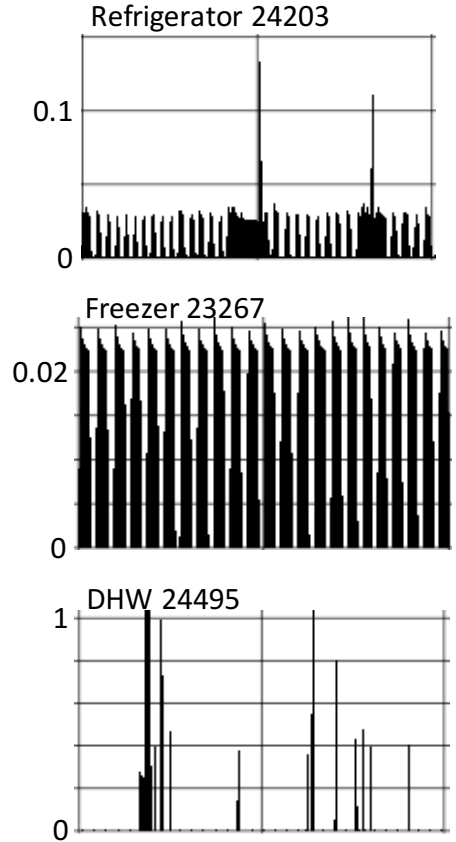

Figure 2. Load profile of TCL appliances on July 3-4, 2012, showing kWh per each of the 19215 -minute intervals. Note the variability in energy usage over time: (a) two refrigerators; (b) two freezers, one with a long run time; and (c) two DHW heaters showing typically low run times. Notes: House numbers appear after appliance names. The y-axes auto-scale changes reflect load diversity within and among houses and appliance types.

\section{Methodology}

For all types of TCL appliances, a simple generic equipment operational model was used to accurately represent diversity among start time, frequency of use, duration of use, load, energy consumption, and weekday vs. weekend operation. To create load-shaping opportunity estimates at 15minute intervals throughout the day, NEEA RBSA TCL appliances were assumed to have a future ability to 
automatically execute consumer choices during periods of high and low energy costs. In contrast, although dishwashers, clothes washers, clothes dryers, etc., are included in NEEA RBSA data, these are excluded because pricing alone may not automate their participation; humans usually initiate the start/stop of such discretionary-start appliances.

\section{A. Modeling NEEA RBSA Data}

To preserve the diversity in the NEEA RBSA data set, each TCL appliance is viewed as a contributor to a desired load increase or decrease based on TCL $O N$ or $O F F$ state over time. For example, assuming contiguous nonoverlapping temperature control set points for a DHW heater, as shown in Table I, the $O N$ or $O F F$ state of each appliance is used to calculate the load increase or decrease opportunity at any point in time given an electricity price change. A second assumption is that the TCL appliance is always operating within its control differential (dead band), meaning that the water temperature is within the $O N$ and $O F F$ limits and never in the "Not Available" region of Table I.

TABLE I. SAmple DHW CONTIGUOUS Nonoverlapping SET Points

\begin{tabular}{|c|c|c|}
\hline Temp. $\left({ }^{\circ} \mathbf{F}\right)$ & High \$/kWh & Low \$/kWh \\
\hline 130 & Always OFF & Turn OFF \\
\hline 129 & Always OFF & Stay ON \\
\hline 128 & Always OFF & Stay ON \\
\hline 127 & Always OFF & Stay ON \\
\hline 126 & Always OFF & Stay ON \\
\hline 125 & Turn OFF & Turn ON \\
\hline 124 & Stay ON & Not Available \\
\hline 123 & Stay ON & Not Available \\
\hline 122 & Stay ON & Not Available \\
\hline 121 & Stay ON & Not Available \\
\hline 120 & Turn ON & Not Available \\
\hline 119 and below & Not Available & Not Available \\
\hline
\end{tabular}

Appendix B contains a simple DHW heater model of contiguous nonoverlapping set points.

Whenever the price of electricity changes, from high to low or low to high, TCL appliances react as described in the DHW example above and in Fig. 3. This logic is applied to every appliance to create a time series of "Load Add" and "Load Shed" opportunities, which are summed for a single house or group of houses.

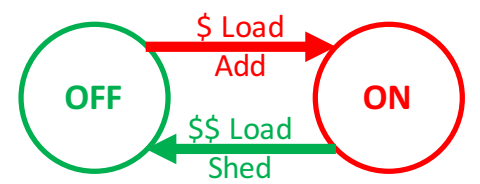

Figure 3. Two-state TCL model showing load additon (in red) or load shedding (in green), given high-to-low or low-to-high pricing changes. One dollar sign indicates low price; two dollar signs indicate high price.

At any point in time, an appliance is either $O N$ or $O F F$. Looking ahead over $n$ time steps at an individual appliance's load over time, as shown in Fig. 2, a maximum load, $L_{\max }$, can be determined. Likewise, at any time, $t$, the logic sequences shown in Fig 3. can be evaluated to calculate the load add or shed opportunity, $O P$, based on the aforementioned assumptions. Given a high price of electricity, if an appliance is $O F F$, it is incentivized to turn $O N$ with a low price of electricity, and the turning $O N$ results in a load addition, $L_{a d d}$, equal to $L_{\max }$, as in:

$$
L_{\text {add }}^{\text {appliance }}=O P_{\text {add load }}^{\text {OFF appliance }}=L_{\max (t, t+n)}^{\text {appliance }}
$$

Given a low price of electricity, if an appliance is $O N$ with a current load, $L_{t}$, it is incentivized to turn $O F F$ with a high price of electricity, and the turning $O F F$ results in a load shedding, $L_{\text {shed, }}$, equal to negative $L_{t}$, as in:

$$
L_{\text {shed }}^{\text {appliance }}=O P_{\text {shed load }}^{\text {ON appliance }}=-L_{t}^{\text {appliance }}
$$

In this model, if a partial load is present, then no load addition is applied, even though $L_{t}$ is less than $L_{\max }$.

Summing among TCL appliances in a specific home yields upper and lower limits of aggregate load that may be added or shed as in (3) and (4):

$$
\begin{aligned}
& L_{\text {add }}^{\text {home }}=\sum_{T C L \text { appliances }} L_{\text {add }}^{\text {appliance }} \\
& L_{\text {shed }}^{\text {home }}=\sum_{T C L \text { appliances }} L_{\text {shed }}^{\text {appliance }}
\end{aligned}
$$

Summing among a group of homes yields an aggregate load that may be added or shed as in (5) and (6):

$$
\begin{aligned}
& L_{\text {add }}^{\text {homes }}=\sum_{\text {homes }} L_{\text {add }}^{\text {home }} \\
& L_{\text {shed }}^{\text {homes }}=\sum_{\text {homes }} L_{\text {shed }}^{\text {home }}
\end{aligned}
$$

To simplify the above, the concept of a duty cycle is used to describe the $O N$ and $O F F$ behavior of a TCL appliance over time. Duty cycle, $D C$, describes the behavior of a device that operates intermittently rather than continuously; it is the fraction of time a device is $O N$ divided by the total time, as in:

$$
D C_{t, t+n}=(\text { ON time })_{t, t+n} /(\text { total time })_{t, t+n}
$$

Over time, an appliance with a low duty cycle typically has a low opportunity to shed load and high opportunity to add load. Conversely, an appliance with a high duty cycle typically has a high opportunity to shed load and a low opportunity to add load. These relationships are shown in (8) and (9):

$$
\begin{gathered}
O P_{t, t+n}^{\text {appliance add load }}=1-D C_{t, t+n}^{\text {appliance }} \\
O P_{t, t+n}^{\text {appliance shed load }}=D C_{t, t+n}^{\text {appliance }}
\end{gathered}
$$

The opportunity to add and shed load may be summed among TCL appliances and homes as in (3), (4), (5), and (6) to yield the instantaneous aggregate upward and downward loadshaping opportunity. It is critically important to note that following the instantaneous change, the future operation of a 
TCL appliance cannot be controlled continuously. Out of scope of this paper is determining the resulting load add and shed opportunities after a price change, wherein the subsequent load shaping opportunities depend on the updated state of each individual TCL appliance that participated in the load increase or decrease event [11].

\section{B. Scaling Up NEEA RBSA Data}

Diverse profiles from tens to millions of homes are required as part of realistic joint optimization of generation, transmission, distribution, storage, and load. In future scaling up of NEEA RBSA data, consideration must be given to preserving diversity such as consumer usage patterns and types and ages of appliances. This is necessary because neither the observed nor predicted demand can be adequately represented by a simple time-series average of all user demands. In scaling up NEEA RBSA loads, the goal is not to find singular expected values at points in time but to specify a realistic probability distribution function of every appliance load over time. By specifying a stochastic model over time, the richness of individual NEEA RBSA TCL appliances is preserved so that models and simulations most accurately reflect future electrical demand along with corresponding load increase and reduction opportunities.

As stated by [12], traditional stochastic methods that are crafted to capture measures such as mean, variance, and skew may fail to reproduce significant spectral properties of the observed data. This failure to reproduce spectral properties can lead to inaccurate estimation of load. As such, a wavelet autoregressive method (WARM) is being developed to capture and recreate nonstationary and quasi-periodic behavior involving hour of day, day of week, grocery shopping cycles, timing of house chores, seasonal weather patterns, family vacations, and varying numbers of occupants.

As a first step, the NEEA RBSA TCL appliance data is decomposed via continuous wavelet transform, and components are identified based on peaks in the global (timeaveraged) wavelet spectrum, as shown in Fig. 4. The approach decomposes a time series into various components at several frequencies via the wavelet transform, thus giving the power (or variance) of the original data in the frequency and time domains. The continuous wavelet transform for some time series, $x_{t}$, is defined as:

$$
X(a, b)=a^{-\frac{1}{2}} \int_{-\infty}^{+\infty} \chi_{t} \varphi^{*}\left(\frac{t-b}{a}\right) d t
$$

where $a$ is a scale parameter, $b$ is the shift parameter, and $\varphi^{*}$ is the wavelet function [13]. The $(*)$ denotes a complex conjugate. The Morlet wavelet is chosen, given by:

$$
\varphi(\eta)=\pi^{-1 / 4} \exp \left(i \omega_{0} \eta\right) \exp \left(-\frac{\eta^{2}}{2}\right)
$$

where $\omega_{0}$ and $\eta$ are nondimensional frequency and time parameters, respectively [14]. By substituting $\left(\frac{t-b}{a}\right)$ for $\eta$ in (11), the shifted and dilated form of the mother wavelet is given [14]-[17]. Equation (10) can be thought of as a series of convolutions between the wavelet function (11) and the original time series at all points for a variety of wavelet scales. To simplify the process, all convolutions can be completed simultaneously at a given scale by the convolution theorem. By doing so, the wavelet transform is defined as the inverse Fourier transform of the product of the data and the wave function in the Fourier space. A contour plot of the wavelet transform gives the wavelet spectrum at different frequencies over time, and a global wavelet spectrum shows average variance strength at each frequency across time. Details on wavelet-based time-series estimation can be found in [14].
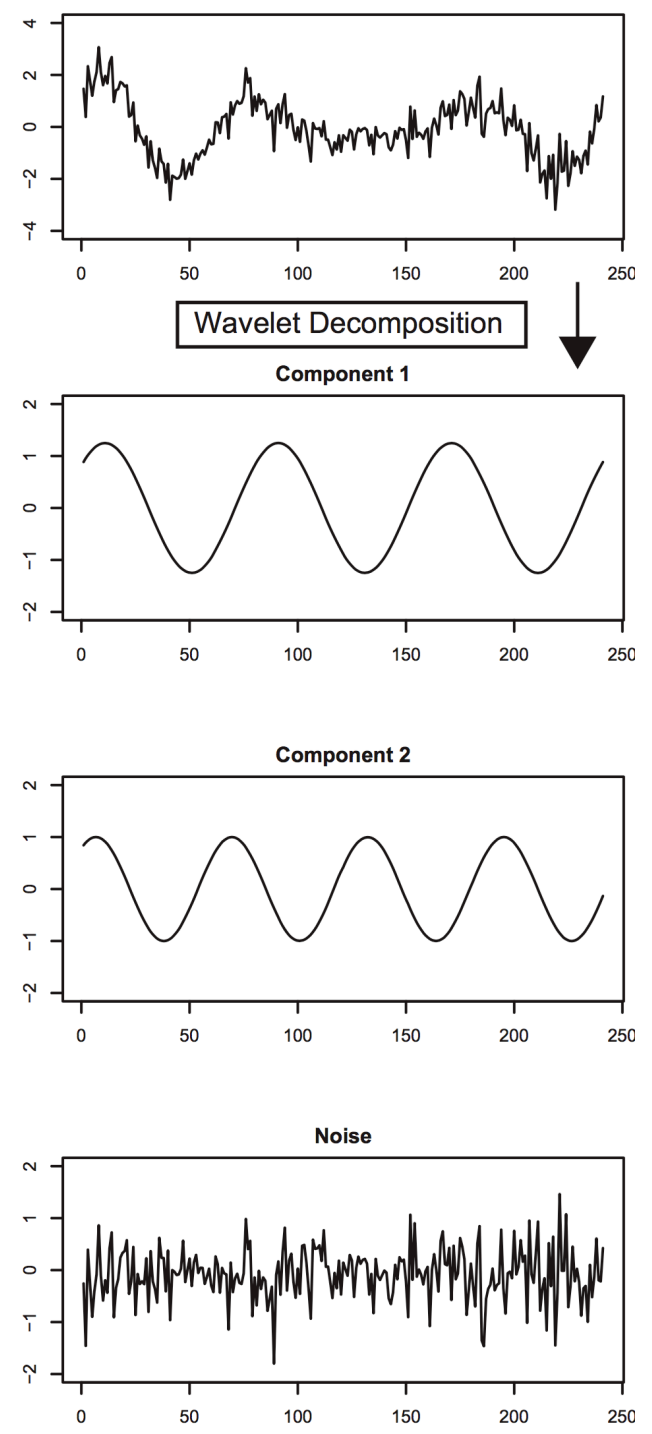

Figure 4. Example diagram of wavelet decomposition as a first step in the enhanced WARM. Wavelets are localized in both time and frequency whereas the standard Fourier transform is only localized in frequency.

\section{RESULTS}

In the NEEA RBSA study, $55 \%$ of homes have electric DHW heating, and there is an average of 1.3 refrigerators per home plus 0.53 separate freezers per home. Average energy usage by TCL appliance for period 2Q2012-1Q2013 (inclusive) is shown in Table II, wherein $E B$ is the error bound on the mean, $N$ is the number of appliances, and $D C$ is the duty cycle. 
TABLE II. TCL ANNUAL ENERgy USAGE AND DUTy CyCle

\begin{tabular}{|l|r|r|c|c|}
\hline \multicolumn{1}{|c|}{ Appliance Type } & $\begin{array}{c}\text { Mean } \\
(\mathrm{kWh} / \mathrm{yr})\end{array}$ & EB & N & DC \\
\hline Electric DHW & 3,043 & 212 & 44 & $22 \%$ \\
\hline Freezer & 609 & 60 & 46 & $51 \%$ \\
\hline Primary refrigerator & 604 & 25 & 99 & $75 \%$ \\
\hline Secondary refrigerator & 600 & 110 & 21 & $56 \%$ \\
\hline
\end{tabular}

Error bounds (EBs) for Mean at the $90 \%$ confidence level.

For every 15-minute interval, (1) and (2) are evaluated to calculate the ability of each specific TCL appliance to add and shed load using a look-ahead interval of 24-hours for $L_{\max }$. Likewise, for each specific home, results are summed among TCL appliances using (3) and (4) to calculate the upper and lower limits of load shaping, as shown in Fig. 5 and Table III (six-hours chosen for visual clarity of chart).

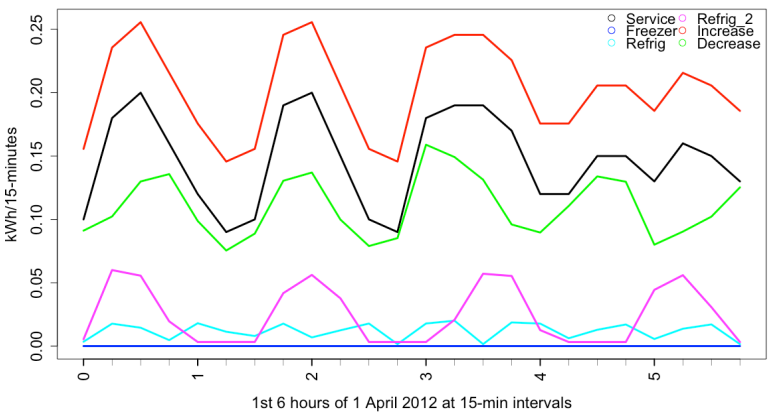

Figure 5. Load profile of NEEA RBSA home 13019 at 15-minute intervals. The black line is the whole-building electric service, the portion leading up to the red line is the instantaneous load that can be added, and the portion descending to the green line is the instantaneous load that can be shed. Loads of individual TCL appliances in the home appear at the bottom of the graph.

TABLE III. LOAD-SHAPING OPPORTUNITIES FOR HOME 13019 BASED ON 15-MINUTE INTERVALS DURING FIRST SIX HOURS OF APRIL 1, 2012

\begin{tabular}{|c|l|l|l|}
\hline Opportunity & Max & Min & Mean \\
\hline Increase load $[\mathrm{kW}]$ & 0.800 & 0.360 & 0.587 \\
\hline Decrease load $[\mathrm{kW}]$ & 0.636 & 0.302 & 0.442 \\
\hline
\end{tabular}

To evaluate load shaping among groups of homes, results from individual homes are summed using (5) and (6). Summing whole-building electric service as well as the upper and lower limits, among the 14 NEEA RBSA homes exhibiting best data quality, yields an aggregate load that may be added or shed at any point in time, as shown in Fig. 6.

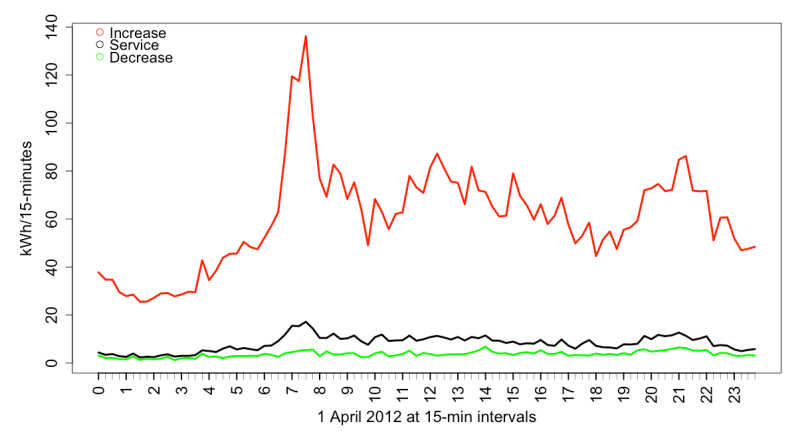

Figure 6. Aggregate load profile of 14 NEEA RBSA homes at 15-minute inervals. The black line is the sum of all electric use, the portion leading up to the red line is the possible load that can be added, and the portion descending to the green line is the possible load that can be shed. The red spikes indicate opportunities to add load, for example, following completion of DHW heating that resulted from early morning widespread synchronized

use of hot water. Mid-day and evening opportunities are also evident.

Summing across multiple houses shows that significantly more load can be added than shed at any point in time. This is mostly attributable to a DHW heater's low duty cycle (Table II) and high instantaneous load, which is on the order of 10 to 40 times greater than that of refrigerators and freezers (Fig. 2).

The wavelet visualization for a single DHW heater shown in Fig. 7 is based on 2 years of 15 -minute intervals from 2Q2012 through 1Q2014 inclusive. In Figs. 7-9, the left plot is the wavelet local power spectrum, the $x$-axis is the wavelet location in time, and the $y$-axis is the wavelet period in years. The blue color indicates the lower power spectra, the red color the higher, and the arch is the cone of influence beyond which there is limited data confidence. The companion graph at right is the global power spectrum; the faint dashed and solid gray lines at the $90 \%$ and $95 \%$ confidence levels are from red noise power spectrum weighted toward low frequencies with no single preferred period.
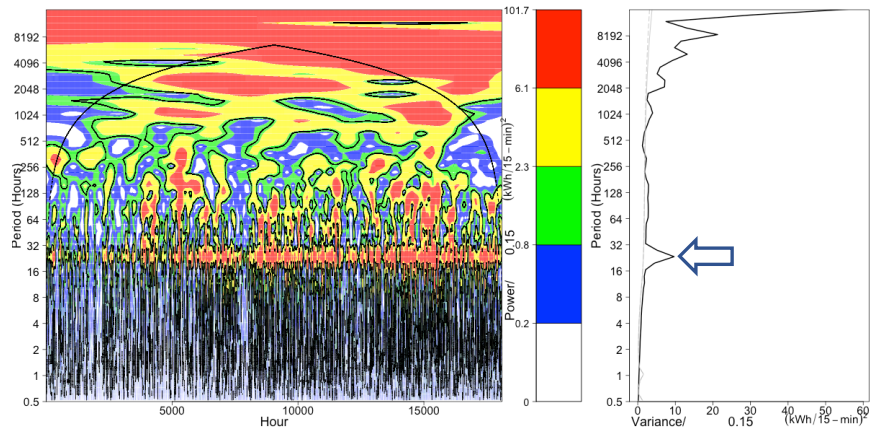

Figure 7. Plots for the DHW heater in NEEA RBSA home 22284. Red areas indicate periods of greater hot water usage. Red in the 24-hour period indicates daily usage. In the right graph, the peak next the arrow corresponds to sustained usage on left graph. Lack of red areas in the 24-hour period at far left indicates that less hot water was used on a daily basis in 2Q2012.

The wavelet visualization for a single refrigerator shown in Fig. 8 is based on 1 year of 15 -minute interval data from 2Q2012 through 1Q2013 inclusive.
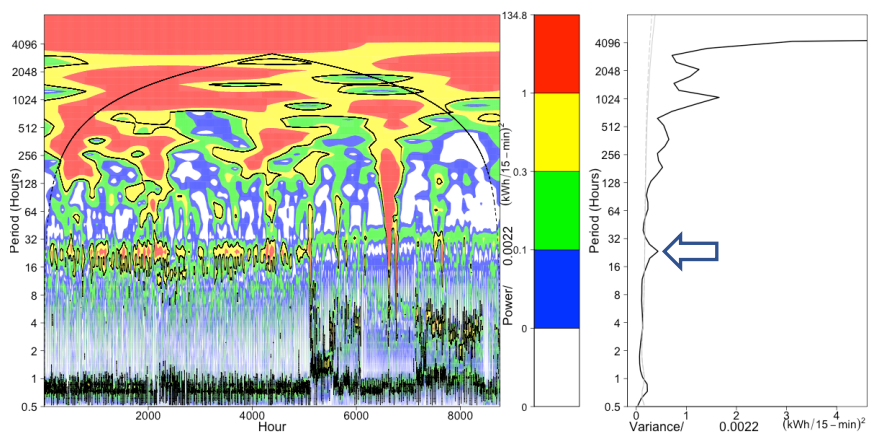

Figure 8. Plots for the refrigerator in NEEA RBSA home 23049. Red areas indicate greater load around 24-hour periods, particularly during the summer, and also around Christmas (note the red vertical spike). As expected, the refrigerator turns on more often and at higher loads during the summer. 
The wavelet visualization for a single freezer shown in Fig. 9 is based on 1 year of 15-minute interval data from 2Q2012 through 1Q2013 inclusive.

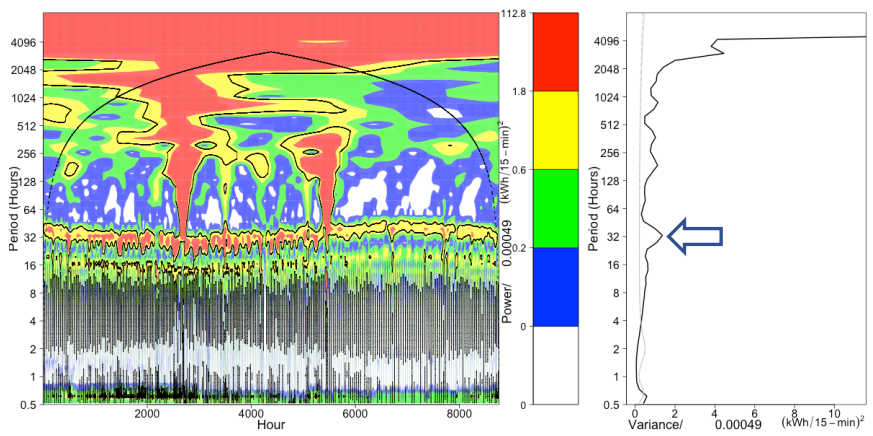

Figure 9. Plots for the freezer in NEEA RBSA home 21143. Two large red areas within the cone of influence indicate high-load, long run times in July and November. The increased red areas and slight sinusoidal dip (at left) in the 24 to 48-hour period together indicate that the freezer load increases at shorter intervals in the summer. The solid green period across the bottom indicates that the freezer has a unity duty cyle (i.e., is always on). Note that when compared over similar periods, a benefit of wavelet visualizations is that they convey more comprehensive information than the barplots in Fig. 2.

\section{CONCLUSIONS AND OUTLOOK FOR FUTURE WORK}

Using empirical data, an ARLS model allowing for consumer-configurable preferences predicts the upper and lower opportunity limits of TCL shaping for individual and groups of NEEA RBSA single-family homes in the Pacific Northwest of the United States. Empirical data were explored, resulting in several interesting statistics and features, including the simple relationship between duty cycle and opportunity to add or shed load.

Wavelet analysis was applied to capture and view diverse spectral components of load related to conditions such as type and age of homes and appliances, potential location of appliances in conditioned vs. nonconditioned spaces, occupancy patterns, hour of day, day of week, seasons, holidays, shopping cycles, home chore cycles and vacations.

Near-term work will continue the development of the generic equipment operational model and WARM simulation to faithfully represent NEEA RBSA TCL appliance behavior. The ARLS model will be expanded beyond the estimation of load increase/decrease opportunities to include estimations of TCL appliance future states immediately following a change in price.

In parallel, long-term work will scale the ARLS model to thousands and millions of homes while including load-shaping contributions from grid-friendly automation that: (1) manages optimal charging and discharging of fixed and mobile (vehicle) batteries based on price of electricity, expected loads, and driving distance; (2) curtails distributed solar photovoltaic generation in response to negative electricity pricing intended to raise net load; and (3) time-shifts HVAC operation to take advantage of the specific heat capacity of residential furnishings and building envelopes [18] for all IECC zones [10].
The future ARLS model will include a broad set of dispatchable loads for predicting the upper and lower limits of load shaping for all homes in the United States. The culminating phases of this work will: (1) include classification and clustering of individual residential demand and (2) leverage extensive National Renewable Energy Laboratory electric grid models to assess the value of ARLS in the joint optimization of distribution, transmission, RES and conventional generation, storage, and load, while using buildings as sensors in optimizing weather and load forecasts.

\section{REFERENCES}

1. D. P. Chassin and C. Posse, "Evaluating North American electric grid reliability using the Barabási-Albert network model," Physica A: Statistical Mechanics and its Applications, vol. 355, pp. 667-677, 2005.

2. M. Liebrich, "In Search of the Miraculous", unpublished, Presented at Bloomberg New Energy Finance Summit, New York, 5 April 2016. [Online]. Available: http://www.bbhub.io/bnef/sites/4/2016/04/BNEFSummit-Keynote-2016.pdf

3. A. Verbruggen and V. Lauber, "Basic concepts for designing renewable electricity support aiming at a full-scale transition by 2050 ," Energy Policy, vol. 37, pp. 5732-5743, 2009.

4. T. Boßmann and E. Eser, "Model-based assessment of demand-response measures-A comprehensive literature review," Renewable and Sustainable Energy Reviews, vol. 57, pp. 1637-1656, 2016.

5. S. Darby and E. McKenna, "Social implications of residential demand response in cool temperate climates", Energy Policy, vol. 49, pp. 759$769,2012$.

6. L. Hirth, "The market value of variable renewables: The effect of solar wind power variability on their relative price," Energy economics, 2013. [Online]. Available:

http://www.sciencedirect.com/science/article/pii/S0140988313000285

7. M. Nicolosi and M. Fürsch, "The impact of an increasing share of RES-E on the conventional power market - the example of Germany," Zeitschrift für Energiewirtschaft, 2009. doi:10.1007/s12398-009-0030-0

8. NEAA. 2011 Building Stock Assessment: Single-family Characteristics and Energy Use, Northwest Energy Efficiency Alliance, 2012.

9. NEEA. 2014 Residential Building Stock Assessment Metering Study, Northwest Energy Efficiency Alliance, 2014.

10. ICC, US DOE. IECC Climate Zone Map, 2012.

11. K. McKenna and A. Keane, "Residential Load Modeling of Price-Based Demand Response for Network Impact Studies," IEEE Transactions on Smart Grid, vol. 7 (5), pp. 2285-2294, Sep. 2016.

12. K. C. Nowak, B. Rajagopalan and E. Zagona, "Wavelet Auto-Regressive Method (WARM) for multi-site streamflow simulation of data with nonstationary spectra," Journal of Hydrology, vol 410 (1), 1-12, 2011.

13. H. H. Kwon, U. Lall, A. F. Khalil, "Stochastic simulation model for nonstationary time series using an autoregressive wavelet decomposition: applications to rainfall and temperature," Water Resources Research, vol. 43 (5), 2007.

14. C. Torrence and G. P. Compo, "A practical guide to wavelet analysis," Bulletin of the American Meteorological society, vol. 79 (1), pp. 61-78, 1998.

15. P. Addison, The Illustrated Wavelet Transform Handbook, New York: Taylor \& Francis, 2002.

16. H. H. Kwon, U. Lall, J. Obeysekera, "Simulation of daily rainfall scenarios with interannual and multidecadal climate cycles for South Florida," Stochastic Environmental Research and Risk Assessment, vol. 23 (7), pp. 879-896, 2009.

17. C. Torrence, P. J. Webster, "The annual cycle of persistence in the El Nino Southern Oscillation," Quarterly Journal of the Royal Meteorological Society, vol. 124 (550), pp. 1985-2004. Jul. 1998.

18. C. D. Corbin, "Assessing Impact of Large-Scale Distributed Residential HVAC Control Optimization on Electricity Grid Operation and Renewable Energy Integration," Ph.D. dissertation, Dept. Civil, Envir. and Arch. Eng., Univ. Colorado, Boulder, 2014. 
VII. APPENDiX A: ThreE SAMPLE NEEA RBSA DATA RECORDS FOR ONE HOME (SiteID 24808).

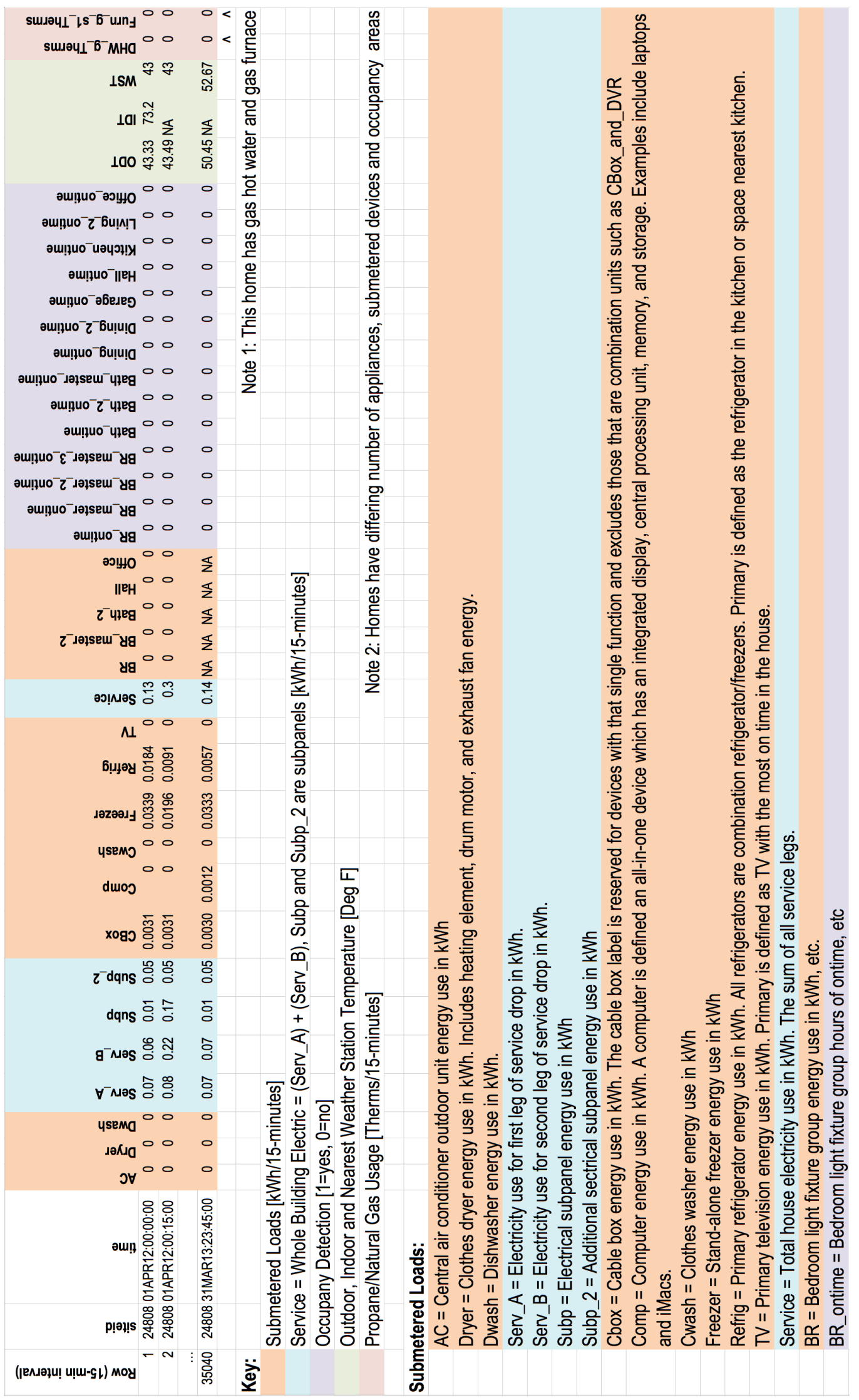


VIII. APPENDIX B: SimPLE DHW HEATER MODEL WITH CONTIGUOUS NONOVERLAPPING SET POINTS

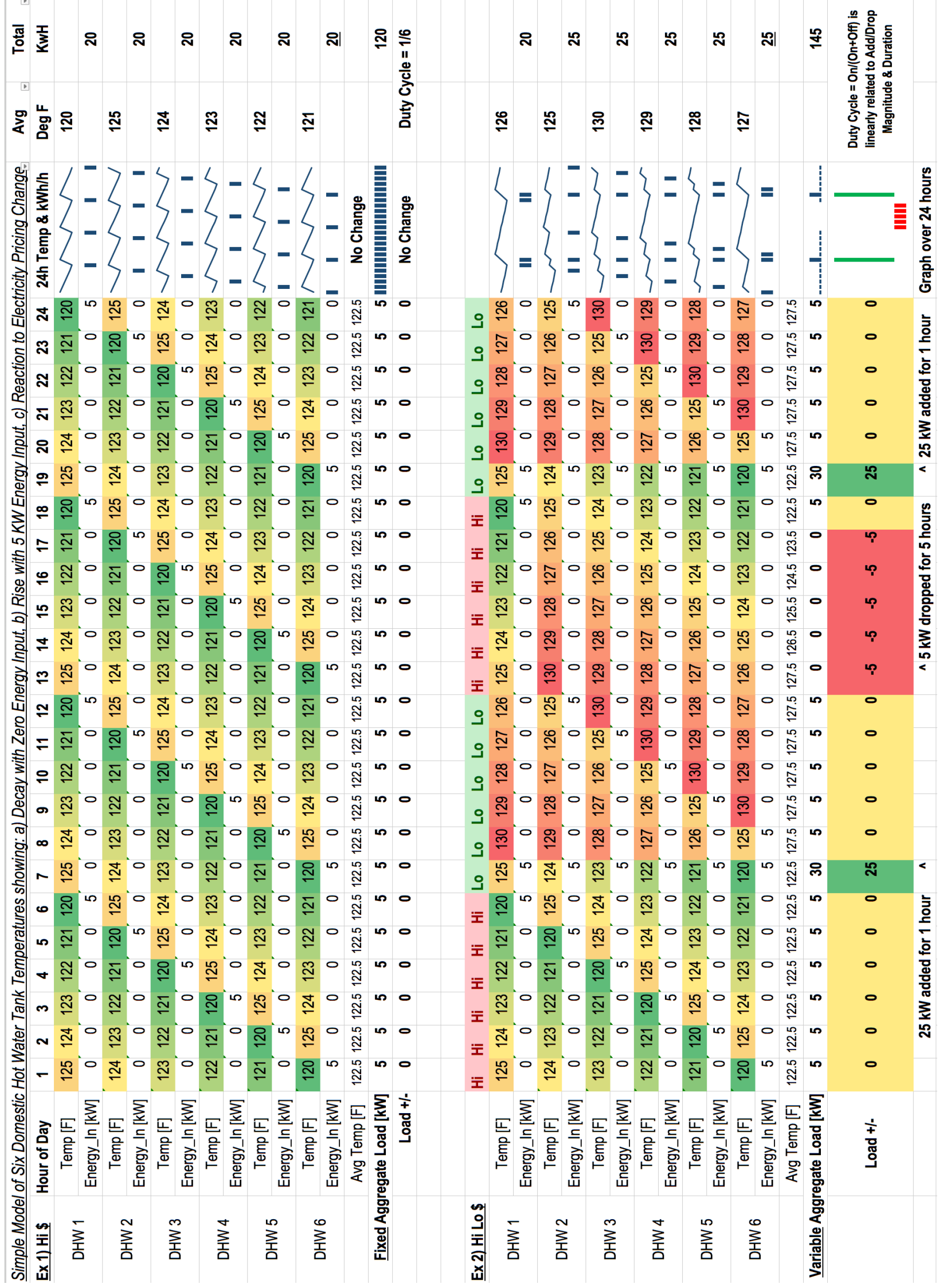

